\title{
Effect of losartan on Doppler sonography indices in kidney transplant patients: A randomized clinical trial
}

\author{
Nader Nouri-Majalan' \\ Reza Nafisi ${ }^{2}$ \\ Sarasadat Moghadasi- \\ Mousavi' \\ 'Department of Nephrology; \\ 2Department of Radiology, Shahid \\ Sadoughi Medical University, \\ Yazd, Iran
}

\begin{abstract}
Background: Color Doppler sonography indices, such as resistive index (RI) and pulsatility index (PI), can predict arteriosclerosis of internal renal vessels after kidney transplantation. Angiotensin II receptor antagonists, however, may have antiatherogenic effects. We therefore assessed the effects of losartan on RIs of renal allografts.

Methods: We compared duplex sonographic measurements in renal allograft recipients (30 males, 20 females) from living donors randomized to a losartan (25 mg twice daily) or a control group.
\end{abstract}

Results: The patients in the two groups had similar baseline characteristics, and 49 (24 in the losartan and 25 in the control group) completed 12 months of follow-up. After 12 months, the losartan and control groups did not differ significantly in mean RI $(0.71 \pm 0.06$ vs $0.69 \pm 0.07$, $\mathrm{P}=0.4)$ or $\mathrm{PI}(1.3 \pm 0.25$ vs $1.29 \pm 0.28, \mathrm{P}=0.8)$ of the intrarenal artery and mean $\mathrm{RI}(0.74 \pm 0.07$ vs $0.72 \pm 0.07, \mathrm{P}=0.3)$ and $\mathrm{PI}(1.5 \pm 0.3$ vs $1.4 \pm 0.34, \mathrm{P}=0.3)$ of the main artery.

Conclusions: Losartan had no effect on Doppler sonography indices. Longer follow-up, however, may be needed to confirm this finding.

Keywords: Doppler ultrasonography, kidney transplantation, losartan

\section{Introduction}

Chronic allograft nephropathy is characterized by fibrogenesis or the accumulation of extracellular matrix (glomerular, arteriolar, and interstitial), similar to findings in other chronic diseases of the kidneys and other organs. ${ }^{1-3}$ Histologically, such kidneys show evidence of arterial intimal and medial fibrosis, arteriolar lesions, glomerulosclerosis, and interstitial fibrosis with tubular atrophy. The renin-angiotensin system (RAS) is involved in these changes, ${ }^{4}$ as well as in the initiation and amplification of atherosclerosis leading to cardiovascular diseases ${ }^{5,6}$ and mild renal impairment. ${ }^{7}$ Angiotensin II antagonists dramatically decrease atherosclerosis in the cardiovascular system ${ }^{8}$ and in the kidneys. ${ }^{7}$ Measurements of resistive indices (RIs) of intrarenal arteries of allograft kidneys are used to assess intrarenal damage, target organ damage related to hypertension, and subclinical atherosclerosis of other organs. ${ }^{9}$ However, the effects of angiotensin II receptor blockers on RIs of allograft kidneys are unclear. We therefore determined the effect of losartan on RIs of renal allografts using color Doppler sonography.

\section{Materials and methods}

\section{Patients and study design}

Between February and May 2006, we screened all consecutive unrelated living renal transplant recipients $>18$ years old who had received transplants at least six months earlier. All patients were from the outpatient clinic of the nephrology center at Sadoughi Hospital, Sadoughi Medical University in Yazd, Iran. Exclusion criteria included a history of taking 
angiotensin-converting enzyme inhibitors (ACEIs) and/or angiotensin II blockers (ARBs), serum creatinine $>2.5 \mathrm{mg} / \mathrm{dL}$, serum potassium $>5.5 \mathrm{meq} / \mathrm{L},>80 \%$ stenosis in the main artery of the transplanted kidney, and presence of hydronephrosis. No patient had a history of smoking. All patients were taking cyclosporine and prednisolone, and some were taking mycophenolate mofetil $(n=39)$ or azathioprine $(n=9)$.

The study protocol was approved by the ethics committee of our institution and informed consent was obtained from each patient. A randomized clinical trial was performed.

Patients were randomized to receive losartan $50 \mathrm{mg}$ daily or no losartan. Patients with hypertension were allowed medication, except for ACEIs and ARBs. Blood pressure, body mass index (BMI), hematochemical parameters, and Doppler sonography indices were evaluated at baseline and after six and 12 months of treatment. BMI was calculated as weight $(\mathrm{kg}) /$ height $\left(\mathrm{m}^{2}\right)$. Mean arterial blood pressure (MAP) and pulse pressure index (PPI; systolic blood pressure - diastolic blood pressure/systolic blood pressure) were calculated. Cyclosporine trough levels were measured by an automated clinical chemistry analysis system.

\section{Doppler examination}

Doppler US examinations, including measurements of RI and PI, were performed at least 12 hours after the last dose of cyclosporine. All color Doppler examinations were performed by a single investigator, blinded to patient treatment, using an Aloka SSD-1700 machine with a 3.5-MHz convex-array transducer, with the patient in the supine position. Choice of using one single investigator for all color Dopppler examinations was to avoid systematic faults. Intrarenal Doppler spectra of the interlobar and segmental arteries were obtained at three representative locations and spectra of the main renal artery were obtained from three points, at the proximal, middle, and distal parts. RI was calculated as (peak systolic frequency shift - minimum diastolic frequency shift)/peak systolic frequency shift; and PI as (peak systolic frequency shift - minimum diastolic frequency shift)/mean frequency shift. The average RI and PI were computed to yield overall RI and PI values for the renal transplants. The criteria for significant $(>70 \%)$ artery stenosis was a ratio $>3$ of stenotic area peak systolic velocity to external iliac artery peak systolic velocity, coupled with post-stenotic disturbed flow.

\section{Statistical analysis}

A sample population of 25 patients in each group was planned to enable achievement of $80 \%$ power with $\alpha=0.05$ for detecting at least a $10 \%$ decrease in RI in the losartan group. ${ }^{10}$
All data were analyzed with SPSS 13 (SPSS Inc, Chicago, IL, USA). Data are expressed as means \pm SDs. Student's t-test for unpaired data, or chi-square analysis, were used as appropriate, to assess differences between groups. In addition, multiple regression analysis was performed among the study groups and other clinical variables.

\section{Results}

Between February and May 2006, 68 consecutive patients received living renal transplants from unrelated donors. Patients were excluded if they had a history of treatment with ACEIs or ARBs $(n=12)$, or serum creatinine $>2.5 \mathrm{mg} / \mathrm{dL}$ $(n=6)$. None of these patients had $>80 \%$ stenosis in the main renal artery and none had hydronephrosis. Fifty patients (30 males, 20 females) were enrolled in the study, with 25 randomized to losartan and 25 patients to no treatment. The follow-up was 12 months; one patient in the losartan group was lost to follow-up. One patient in the losartan group had hypotension and had to discontinue losartan. During follow-up, there were no acute rejection episodes and no graft losses.

The two groups had similar baseline characteristics (Table 1). The effects of losartan on RI and PI of the intrarenal and main arteries after six and 12 months are shown in Table 2. Multiple linear regression analysis revealed that losartan had no effect on intrarenal RI $(\mathrm{P}=0.83)$ and PI $(\mathrm{P}=0.87)$ after adjustment of age, sex, BMI, time since transplantation, diabetes, hypertension, MAP, serum creatinine and cyclosporine concentration after one year follow-up.

After 12 months, there were no significant differences between the control and losartan groups in MAP (89 $\pm 15.7 \mathrm{~mm} \mathrm{Hg}$ vs $90 \pm 14.3 \mathrm{~mm} \mathrm{Hg}$; $=0.89$ ), serum creatinine $(1.1 \pm 0.23 \mathrm{mg} / \mathrm{dL}$ vs $1.2 \pm 0.34 \mathrm{mg} / \mathrm{dL} ; \mathrm{P}=0.38)$, serum potassium $(4.6 \pm 0.44 \mathrm{meq} / \mathrm{L}$ vs $4.4 \pm 0.43 \mathrm{meq} / \mathrm{L} ; \mathrm{P}=0.11)$, and cyclosporine $(181 \pm 51.3 \mathrm{ng} / \mathrm{mL}$ vs $150 \pm 57.6 \mathrm{ng} / \mathrm{mL}$; $\mathrm{P}=0.063$ ) concentrations.

The adverse effects of losartan consisted of hypotension in one patient, hyperkalemia in one, and muscle spasm in one.

Some important baseline characteristics (age, sex, BMI, time since transplantation, episode of acute rejection before study, diabetes, serum creatinine) in twelve patients who were excluded because of taking ACEIs and ARBs were not significantly different by comparison with the study patients (data is not shown).

\section{Discussion}

To our knowledge, this study is the first to assess the effect of an ARB on intrarenal RI and PI. We found, however, 
Table I Baseline characteristics of patients

\begin{tabular}{llll}
\hline Characteristic & Losartan group $(\mathbf{n}=\mathbf{2 5})$ & Control group $(\mathbf{n}=\mathbf{2 5})$ & P value \\
\hline Age (years) & $36 \pm 12$ & $42 \pm 14$ & 0.1 \\
Male sex: no (\%) & $12(48 \%)$ & $18(72 \%)$ & 0.083 \\
Male donor sex: no (\%) & $20(80 \%)$ & $23(92 \%)$ & 0.29 \\
BMI & $24.7 \pm 4.7$ & $25.6 \pm 3.9$ & 0.3 \\
Time since transplant (months) & $47 \pm 36$ & $44 \pm 24$ & 0.6 \\
Episode of AR before study: no (\%) & $1(4 \%)$ & $3(12 \%)$ & 0.6 \\
Diabetes: no (\%) & $3(12 \%)$ & $1(4 \%)$ & 0.3 \\
Hypertension: no(\%) & $13(52 \%)$ & $12(48 \%)$ & 0.7 \\
MAP (mmHg) & $99 \pm 10.5$ & $97 \pm 10$ & 0.33 \\
Serum creatinine $\mathrm{mg} / \mathrm{dL}$ & $1.2 \pm 0.3$ & $1.2 \pm 0.3$ & 0.9 \\
Serum potassium meq/L & $4.3 \pm 0.4$ & $4.5 \pm 0.4$ & 0.4 \\
Cyclosporine level $(\mathrm{ng} / \mathrm{mL})$ & $187 \pm 67$ & $204 \pm 75$ & 0.9 \\
\hline
\end{tabular}

Abbreviations: AR, acute rejection; BMI, body mass index; MAP, mean arterial pressure.

that losartan had no effect on intrarenal RI and PI after one year.

As previous studies have shown that factors affecting intrarenal RI and PI include age, sex, and $\mathrm{BMI} ;{ }^{9}$ time since transplantation and renal function; ${ }^{11}$ diabetes; ${ }^{12}$ and cyclosporine concentration, ${ }^{13}$ we assessed these factors in our two patient groups. Although there were no significant differences at baseline between the losartan and control groups in these confounding variables, the differences found could be clinically relevant inasmuch as the high standard deviations indicated huge variations that were related to small sample sizes. Therefore, we adjusted the most important factors such as age, sex, BMI, time since transplantation, diabetes, serum creatinine, and cyclosporine concentration. However, after adjustment, losartan had no effect on Doppler sonography indices. At the end of trial, the factors such as sex, serum creatinine and cyclosporine concentration that could change during the study were compared between study groups and no differences make sure that these factors did not confound the effect of losartan on renal indices. Because of ethical issues, we did not perform kidney biopsies at the start of treatment; we therefore could not directly determine the presence of high RI. Randomization likely eliminated any other confounding variables.

RI of transplanted kidneys has been found to correlate with histologically proven arteriolosclerosis of the internal renal vessels, ${ }^{14,15}$ and PI $>0.7$ in transplanted kidneys has been found to correlate with a higher incidence of arteriosclerosis. ${ }^{15}$

Table 2 Doppler sonography indices in the losartan and control groups

\begin{tabular}{|c|c|c|c|c|c|c|}
\hline & \multicolumn{3}{|l|}{ Intrarenal artery } & \multicolumn{3}{|c|}{ Main renal artery } \\
\hline & $\begin{array}{l}\text { Losartan group } \\
(n=25)^{a}\end{array}$ & $\begin{array}{l}\text { Control group } \\
(n=25)\end{array}$ & $P$ value & $\begin{array}{l}\text { Losartan group } \\
(\mathrm{n}=25)^{\mathrm{a}}\end{array}$ & $\begin{array}{l}\text { Control group } \\
(n=25)\end{array}$ & $P$ value \\
\hline \multicolumn{7}{|c|}{ Baseline } \\
\hline RI & $0.7 \pm 0.06$ & $0.69 \pm 0.08$ & 0.8 & $0.72 \pm 0.07$ & $0.72 \pm 0.07$ & 0.9 \\
\hline $\mathrm{PI}$ & $1.2 \pm 0.3$ & $1.3 \pm 0.4$ & 0.3 & $\mathrm{I} .4 \pm 0.3$ & $1.4 \pm 0.32$ & 0.8 \\
\hline \multicolumn{7}{|c|}{6 months } \\
\hline RI & $0.72 \pm 0.06$ & $0.7 \pm 0.06$ & 0.2 & $0.75 \pm 0.04$ & $0.73 \pm 0.07$ & 0.19 \\
\hline $\mathrm{PI}$ & $1.4 \pm 0.3$ & $1.4 \pm 0.3$ & 0.7 & $1.57 \pm 0.28$ & $1.54 \pm 0.3$ & 0.7 \\
\hline \multicolumn{7}{|c|}{12 months } \\
\hline RI & $0.71 \pm 0.06$ & $0.69 \pm 0.07$ & 0.4 & $0.74 \pm 0.07$ & $0.72 \pm 0.07$ & 0.3 \\
\hline $\mathrm{PI}$ & $1.3 \pm 0.25$ & $1.29 \pm 0.28$ & 0.8 & $1.5 \pm 0.3$ & $\mathrm{I} .4 \pm 0.34$ & 0.3 \\
\hline
\end{tabular}

Abbreviations: $\mathrm{RI}$, resistive index; $\mathrm{Pl}$, pulsatility index.

Note: ${ }^{a}$ One patient in the losartan group was lost to follow-up. 
ARBs have been found to show antiatherogenic effects. ${ }^{8,16}$ For example, ARBs had a regressive effect on the formation of fatty streaks in monkeys. ${ }^{17}$

Little is known about the effects of ACEIs on intrarenal RI and PI. ACEIs have been found to reduce PI in normotensive individuals, ${ }^{18}$ and lisinopril has been found to decrease $10 \%$ of renal RI (from $0.61 \pm 0.02$ to $0.56 \pm 0.04$ ) in hypertensive patients after two years follow-up. ${ }^{10}$ We could not show the decrease of RI after one year follow-up and it might be due to short follow-up. However, to our knowledge, there have been no studies on the effects of ARBs or ACEIs on renal Doppler indices in allograft kidneys.

\section{Conclusion}

Although we expected that ARBs would decrease intrarenal RI and PI, we did not observe this effect, which suggests that longer follow-up and larger sample sizes are required.

\section{Disclosure}

The authors declare no conflicts of interest in this work.

\section{References}

1. Campistol JM, Iñigo P, Larios S, Bescos M, Oppenheimer F. Role of transforming growth factor-beta1 in the progression of chronic allograft nephropathy. Nephrol Dial Transplant. 2001;16(Suppl 1):114-116.

2. Solez K, Axelsen RA, Benediktsson H, et al. International standardization of criteria for the histologic diagnosis of renal allograft rejection: the Banff working classification of kidney transplant pathology. Kidney Int. 1993;44:411-422.

3. Matas AJ, Burke JF Jr, DeVault GA Jr, Monaco A, Pirsch JD. Chronic rejection. J Am Soc Nephrol. 1994;4(8 Suppl):S23-S29.

4. Shihab FS, Tanner AM, Shao Y, Weffer MI. Expression of TGF-beta 1 and matrix proteins is elevated in rats with chronic rejection. Kidney Int. 1996;50:1904-1913.
5. Iino $\mathrm{K}$, Ito $\mathrm{H}$. [Use of angiotensin converting enzyme inhibitors and angiotensin receptor blockers in patients with acute coronary syndrome]. Nippon Rinsho. 2006;64:734-741.

6. Fukuda D, Sata M. [Renin-angiotensin system in atherosclerosis]. Nippon Rinsho. 2006;64:805-809.

7. Suganuma E, Zuo Y, Ayabe N, et al. Antiatherogenic effects of angiotensin receptor antagonism in mild renal dysfunction. J Am Soc Nephrol. 2006;17(2):433-441

8. Morawietz H, Erbs S, Holtz J, et al. Endothelial protection, AT1 blockade and cholesterol-dependent oxidative stress: the EPAS trial. Circulation. 2006;114(1 Suppl):I296-I301.

9. Heine GH, Gerhart MK, Ulrich C, Köhler H, Girndt M. Renal Doppler resistance indices are associated with systemic atherosclerosis in kidney transplant recipients. Kidney Int. 2005;68:878-885.

10. Leoncini G, Martinoli C, Viazzi F, et al. Changes in renal resistive index and urinary albumin excretion in hypertensive patients under long-term treatment with lisinopril or nifedipine GITS. Nephron. 2002;90:169-173.

11. Nouri-Majelan N, Nafici R. Duplex sonographic measurements in allografted kidneys: a cross-sectional study. Transplant Proc. 2007;39:1103-1107.

12. Radermacher J, Mengel M, Ellis S, Stuht S, Hiss M, Schwarz A, et al. The renal arterial resistance index and renal allograft survival. $N$ Engl J Med. 2003;349:115-124.

13. Di Palo FQ, Rivolta R, Elli A, Castagnone D, Palazzi P, Abelli P, et al. Effect of cyclosporin A on renal cortical resistances measured by color Doppler flowmetry on renal grafts. Nephron. 1993;65:240-244.

14. Saracino A, Santarsia G, Latorraca A, Gaudiano V. Early assessment of renal resistance index after kidney transplant can help predict longterm renal function. Nephrol Dial Transplant. 2006;21:2916-2920.

15. Mostbeck GH, Kain R, Mallek R, Derfler K, Walter R, Havelec L, et al. Duplex Doppler sonography in renal parenchymal disease. Histopathologic correlation. J Ultrasound Med. 1991;10:189-194.

16. Chen J, Li D, Schaefer R, Mehta JL. Cross-talk between dyslipidemia and renin-angiotensin system and the role of LOX-1 and MAPK in atherogenesis studies with the combined use of rosuvastatin and candesartan. Atherosclerosis. 2006;184:295-301.

17. Takai S, Jin D, Sakaguchi M, Muramatsu M, Miyazaki M. The regressive effect of an angiotensin II receptor blocker on formed fatty streaks in monkeys fed a high-cholesterol diet. J Hypertens. 2005;23:1879-1886.

18. Bardelli M, Jensen G, Volkmann R, Caidahl K, Aurell M. Experimental variations in renovascular resistance in normal man as detected by means of ultrasound. Eur J Clin Invest. 1992;22:619-624. 